\title{
Outcomes of valve replacement with mechanical prosthesis versus bioprosthesis in dialysis patients: A 16-year multicenter experience
}

\author{
Yuki Ikeno, MD, ${ }^{\mathrm{a}}$ Nobuhiko Mukohara, MD, ${ }^{\mathrm{b}}$ Yoshiaki Fukumura, MD, ${ }^{\mathrm{c}}$ Satoshi Tobe, MD, PhD, ${ }^{\mathrm{d}}$ \\ Kunio Gan, MD, ${ }^{\mathrm{e}}$ Hidefumi Obo, MD, PhD, ${ }^{\mathrm{f}}$ Kazunori Yoshida, MD, PhD, ${ }^{\mathrm{g}}$ and Yutaka Okita, MD, PhD ${ }^{\mathrm{a}}$
}

\section{ABSTRACT}

Objective: To evaluate the long-term outcomes of heart valve replacement with mechanical prosthesis (MP) versus bioprosthesis (BP) in patients on dialysis.

Methods: A retrospective review was performed at 7 hospitals. Patients on dialysis who underwent valve replacement were included. Survival, reoperation, bleeding, and embolic events were compared across the MP and BP groups.

Results: Between April 2000 and April 2016, 312 patients on dialysis were enrolled in our study (MP: 94 patients [30.1\%], BP: 218 patients [69.9\%]). Mean follow-up was $3.4 \pm 3.6$ years. Five-year and 10-year survival rates were similar in both groups (MP: $57.4 \pm 5.5 \%$ at 5 years and $46.3 \pm 6.4 \%$ at 10 years, BP: $50.2 \pm 4.1 \%$ at 5 years and $38.8 \pm 4.5 \%$ at 10 years, $P=.305)$. Multivariate Cox hazard analysis demonstrated that diabetic nephropathy (hazard ratio [HR], 1.90; 95\% confidence interval $[\mathrm{CI}], 1.31-2.73, P<.001)$, New York Heart Association functional classification $\geq \mathrm{III}(\mathrm{HR}, 2.16 ; 95 \% \mathrm{CI}, 1.37-3.35, P=.001)$, and mitral valve replacement ( $\mathrm{HR}, 2.36 ; 95 \% \mathrm{CI}, 1.58-3.49, P<.001)$ were significant risk factors for late death. Valve selection was not a significant risk factor. Freedom from valve-related embolic event at 5 years was significantly lower in the MP group (MP: $88.3 \pm 4.3 \%$ at 5 years, BP: $97.2 \pm 1.6 \%$ at 5 years, $P=.007)$. Freedom from valve-related reoperation or hemorrhagic events was similar across both groups.

Conclusions: Valve selection was not associated with late survival outcomes in patients on dialysis. However, BP may have an advantage in preventing embolic events without increasing the incidence of valve-related reoperation when compared with MP. (J Thorac Cardiovasc Surg 2019;158:48-56)



Freedom from embolic events comparing mechanical prosthesis and bioprosthesis.

\section{Central Message}

Survival was similar across patients on dialysis who received mechanical prosthesis and bioprosthesis valve replacement. Bioprosthetic valves had an advantage of decreasing embolic events.

\section{Perspective}

Patients on dialysis with bioprosthetic valves had a lower risk of embolic events, although there was no significant difference between bioprosthetic valves and mechanical valves in regard to late survival, reoperation, or bleeding events. The use of bioprosthetic valves may reduce the burden of anticoagulation in highrisk patients.

See Commentaries on pages 57 and 59.

\footnotetext{
From the ${ }^{\mathrm{a}}$ Department of Cardiovascular Surgery, Kobe University, Kobe; ${ }^{\mathrm{b}}$ Department of Cardiovascular Surgery, Hyogo Brain and Heart Center at Himeji, Himeji; ${ }^{c}$ Department of Cardiovascular Surgery, Tokushima Red Cross Hospital, Tokushima; ${ }^{\mathrm{d}}$ Department of Cardiovasular Surgery, Akashi Medical Center, Akashi; ${ }^{\mathrm{e}}$ Department of Cardiovascular Surgery, Kita-Harima Medical Center, Ono; ${ }^{\mathrm{f}}$ Department of Cardiovascular Surgery, Kakogawa City Hospital, Kakogawa; and ${ }^{\mathrm{g}}$ Department of Cardiovascular Surgery, Nishinomiya Watanabe Cardiovascular Center, Nishinomiya, Japan.

No funding was received for this study.

Received for publication July 1, 2018; revisions received Nov 16, 2018; accepted for publication Nov 28, 2018; available ahead of print Jan 16, 2019.

Address for reprints: Yutaka Okita, MD, PhD, Division of Cardiovascular Surgery, Kobe University Graduate School of Medicine, Department of Surgery, 7-5-2 Kusunoki-cho Chuo-ku, Kobe 650-0017, Japan (E-mail: yutakaokita@ gmail.com). 0022-5223/\$36.00

Copyright (c) 2018 by The American Association for Thoracic Surgery https://doi.org/10.1016/j.jtcvs.2018.11.089
}

The number of patients with end-stage renal disease requiring hemodialysis has increased in incidence over the past several years. In Japan, more than 300,000 patients with end-stage renal disease underwent hemodialysis in 2013 , in comparison with the 100,000 patients requiring hemodialysis in the early 1990s. ${ }^{1}$ In addition, a greater portion of the elderly patients are expected to be on hemodialysis in





Abbreviations and Acronyms
AVR = aortic valve replacement
$\mathrm{BP}=$ bioprosthetic valve
$\mathrm{CI}=$ confidence interval
DVR = combined valve replacement of aortic valve and mitral valve
GI $=$ gastrointestinal
$\mathrm{HR}=$ hazard ratio
MP $=$ mechanical valve
MVR = mitral valve replacement
NYHA $=$ New York Heart Association
SVD = structural valve deterioration
SVR = surgical valve replacement
TAVR $=$ transcatheter aortic valve replacement

the next decade, in line with the development of an aging society. ${ }^{2}$

Patients on dialysis are at a high risk for cardiovascular diseases such as calcified cardiac valves and arteries. ${ }^{3-5}$ Cardiovascular death was the most common cause of death among patients on dialysis in Japan in 2013 $(26.8 \%)$. Valve replacement has been reported to improve the survival of this patient population, even in high-risk patients. ${ }^{6}$ However, prosthetic valve selection in patients on dialysis remains controversial. The survival following heart valve replacement in patients on dialysis is decreased in comparison with patients not on dialysis. ${ }^{7,8}$ The annual mortality rates of patients on dialysis in Japan has remained consistent at $9 \%$ to $10 \% .{ }^{1}$

Although mechanical valves (MPs) are associated with an increased risk of thromboembolism and bleeding complications due to anticoagulation therapy, bioprosthetic valves (BPs) are associated with a shorter durability of the valve secondary to rapid calcification or structural deterioration. ${ }^{9}$ The latest 2014 American Heart Association/American College of Cardiology guidelines for the management of patients with valvular heart disease do not include specific recommendation regarding the valve selection for patients on dialysis. ${ }^{10}$

Few studies exist that compare MP with BP in patients on dialysis. ${ }^{11}$ The purpose of this study is to retrospectively evaluate outcomes in patients on dialysis following heart valve replacement with MP versus BP at multiple centers in Japan.

\section{PATIENTS AND METHODS \\ Study Design}

A retrospective review was performed at Kobe University and 6 affiliate hospitals (Hyogo Brain and Heart Center at Himeji, Tokushima Red Cross Hospital, Akashi Medical Center, Kita-Harima Medical Center, Kakogawa City Hospital, and Nishinomiya Watanabe Cardiovascular Center). Patients on dialysis who underwent valve replacement (aortic valve replacement [AVR], mitral valve replacement [MVR], or combined valve replacement of AVR and MVR [DVR]) were included. We compared survival, reoperation, bleeding, and incidence of embolic events between the MP and BP groups. The Japanese guidelines recommend valve selection based on patient age. ${ }^{12}$ In both AVR and MVR, patients younger than 65 years old were implanted with MP, whereas patients with 65 years old and greater were implanted with BP. In the MP group, the optimal international normalized ratio was set for $<2.5$ in patients receiving AVR and $<3.0$ in patients receiving MVR or DVR. In the BP group, anticoagulation therapy was indicated during the first 3 months following operation. However, the details of prosthetic valve selection and anticoagulation therapy were made by each hospital. Clinical outcomes were compared across both groups, including overall survival, valve-related reoperation, bleeding events, and embolic events. This study protocol was reviewed and approved by the institutional review board in each hospital. An informed consent waiver was granted.

\section{Definitions of Clinical Outcomes}

Structural valve deterioration (SVD) was defined as leaflet stiffening, calcification, reduced effective orifice area, or regurgitation. ${ }^{13}$ Valverelated reoperation was defined as valve surgery for SVD, pannus proliferation, prosthetic valve endocarditis, and prosthetic valve thrombosis.

\section{Statistical Analysis}

All continuous variables are expressed as the mean \pm standard deviation or the median with interquartile range (25th-75th percentile). Categorical variables are expressed as the number $(\%)$ of patients. Categorical variables and continuous variables were analyzed using the $\chi^{2}$ test and Student $t$ test. The values of overall survival, freedom from valve-related death, freedom from bleeding events, and freedom from embolic events were computed using the Kaplan-Meier methods and are expressed as the rate \pm standard error. $P$ values $<.05$ were considered statistically significant differences. Univariate risk factor analysis of overall survival was performed on the cumulative incidence function using Cox regression and hazard ratio (HR) with $95 \%$ confidence interval (CI). A $P$ value $<.05$ in the univariate analysis was defined for the selection variables for multivariate regression analysis of overall survival. Age, sex, and valve selection were included into the model to account for confounding factors. The survival of patients on general dialysis was obtained by the Japanese dialysis population life-table available from the Japanese Society of Dialysis Therapy, ${ }^{14}$ and matching the duration of hemodialysis with the present cohort $(11.0 \pm 8.6$ years). All data analyses were performed with JMP 11.0 software (SAS Institute, Cary, NC).

\section{RESULTS}

\section{Study Population}

From April 2000 to April 2016, 312 patients requiring chronic hemodialysis underwent valve replacement at Kobe University $(\mathrm{n}=82)$ and 6 affiliate hospitals (Hyogo Brain and Heart Center at Himeji $[\mathrm{n}=79]$, Tokushima Red Cross Hospital $[\mathrm{n}=79]$, Akashi Medical Center $[\mathrm{n}=30]$, Kita-Harima Medical Center [ $\mathrm{n}=19]$, Kakogawa City Hospital $[\mathrm{n}=17]$, and Nishinomiya Watanabe Cardiovascular Center $[n=6])$. Follow-up data were obtained by clinical visit, telephone, or written correspondence. A total of 16 patients were lost to follow-up during the study period. Follow-up completeness rate was $94.9 \%$. The mean follow-up period was $3.4 \pm 3.6$ years (median 2.5 years, range $0-15.0$ years). Patients were classified into 2 groups according to valve prostheses, either MP (94 patients [30.1\%]), or BP (218 patients [69.9\%]). 
TABLE 1. Preoperative patient characteristics

\begin{tabular}{|c|c|c|c|c|}
\hline Variables & $\frac{\text { Whole }}{(n=312)}$ & $\frac{\text { Mechanical }}{(n=94)}$ & $\frac{\text { Bioprosthetic }}{(n=218)}$ & $P$ value \\
\hline Age, y & $67.7 \pm 9.6$ & $58.6 \pm 9.3$ & $71.7 \pm 6.5$ & $<.001^{*}$ \\
\hline Female sex & $126(40.4)$ & $32(34.0)$ & $94(43.1)$ & .132 \\
\hline BSA, $m^{2}$ & $1.51 \pm 0.18$ & $1.50 \pm 0.21$ & $1.51 \pm 0.17$ & .625 \\
\hline Duration of hemodialysis, $y$ & $11.0 \pm 8.6$ & $15.3 \pm 10.9$ & $10.0 \pm 7.7$ & $.006^{*}$ \\
\hline Diabetic nephropathy & $121(38.8)$ & $41(43.6)$ & $80(36.7)$ & .252 \\
\hline Insulin use & $48(15.3)$ & $21(22.3)$ & $27(12.4)$ & $.030^{*}$ \\
\hline Hypertension & $210(67.3)$ & $60(63.8)$ & $150(68.8)$ & .839 \\
\hline Dyslipidemia & $60(19.2)$ & $21(22.3)$ & $39(17.9)$ & .365 \\
\hline Previous stroke & $68(21.8)$ & $17(18.1)$ & $51(23.4)$ & .291 \\
\hline Carotid artery stenosis & $19(6.1)$ & $3(3.2)$ & $16(7.3)$ & .137 \\
\hline COPD & $45(14.4)$ & $12(12.8)$ & $33(15.1)$ & .581 \\
\hline Atrial fibrillation & $36(11.5)$ & $10(10.6)$ & $26(11.9)$ & .742 \\
\hline Coronary artery disease & $135(43.2)$ & $37(39.4)$ & $98(45.0)$ & .851 \\
\hline Peripheral artery disease & $49(15.7)$ & $12(12.8)$ & $37(17.0)$ & .867 \\
\hline Active IE & $23(7.3)$ & $14(14.9)$ & $9(4.1)$ & $.002 *$ \\
\hline NYHA $\geq$ III & $68(21.8)$ & $17(18.1)$ & $51(23.4)$ & .291 \\
\hline IABP & $26(8.3)$ & $6(6.4)$ & $20(9.2)$ & .852 \\
\hline PCPS & $9(2.9)$ & $3(3.2)$ & $6(2.8)$ & .833 \\
\hline Intubated & $32(10.3)$ & $10(10.6)$ & $22(10.1)$ & .884 \\
\hline Elective surgery & $232(74.4)$ & $70(74.5)$ & $162(74.3)$ & .977 \\
\hline Ejection fraction, $\%$ & $52.5 \pm 15.7$ & $58.8 \pm 13.3$ & $50.7 \pm 15.9$ & $.009 *$ \\
\hline STS score, $\%$ & $15.5 \pm 15.2$ & $11.5 \pm 11.5$ & $16.5 \pm 16.0$ & .215 \\
\hline EuroSCORE II, \% & $11.2 \pm 13.8$ & $7.7 \pm 10.4$ & $12.3 \pm 14.5$ & .151 \\
\hline Japan Score (30-d mortality, \%) & $19.6 \pm 20.5$ & $15.4 \pm 18.5$ & $20.8 \pm 21.0$ & .256 \\
\hline Japan Score (30-d mortality + major morbidity, \%) & $39.1 \pm 20.7$ & $35.6 \pm 23.2$ & $40.1 \pm 19.9$ & .342 \\
\hline
\end{tabular}

$B S A$, Body surface area; $C O P D$, chronic obstructive pulmonary disease; $I E$, infective endocarditis; NYHA, New York Heart Association functional classification; IABP, intraaortic balloon pumping; PCPS, percutaneous cardiopulmonary support; STS, Society of Thoracic Surgeons; EuroSCORE II, European System for Cardiac Operative Risk Evaluation II. $* P<.05$.

\section{Patient Characteristics}

Preoperative patient characteristics are shown in Table 1. The details of valve selection are summarized in Table E1. The BP group included older patients (MP: $58.6 \pm 9.3$ years, BP: $71.7 \pm 6.5$ years, $P<.001)$. The duration of hemodialysis was significantly longer in the MP group (MP: $15.3 \pm 10.9$ years, BP: $10.0 \pm 7.7$ years, $P=.006$ ). Furthermore, a significant number of patients with insulin use (MP: $22.3 \%$, BP: $12.4 \%, P=.030$ ) and active infective endocarditis (MP: $14.9 \%$, BP: $4.1 \%$, $P=.002$ ) were found in the MP group. Preoperative ejection fraction was greater in the MP group (MP: $58.8 \pm 13.3 \%$, BP: $50.7 \pm 15.9 \%, P=.009)$. Other variables, including the Society of Thoracic Surgeons risk score $(15.5 \pm 15.2)$, European System for Cardiac Operative Risk Evaluation II (11.2 $\pm 13.8 \%)$, and Japan Score $(19.6 \pm 20.5 \%)$ of 30 -day mortality were similar in both MP and BP groups.
Operative data are shown in Table 2. In the entire cohort, 228 patients $(73.1 \%)$ underwent AVR, including 35 patients who underwent concomitant mitral valve repair. MVR was performed in 57 patients $(18.3 \%)$. DVR was performed in 27 patients $(8.7 \%)$. Significantly more patients underwent AVR using BP (MP: 45 patients [47.9\%], BP: 183 patients [83.9\%], $P<.001$ ), whereas MP was used more frequently in MVR (MP: 34 patients [36.2\%], BP: 23 patients [10.6\%], $P<.001)$ and DVR (MP: 15 patients [16.0\%], BP: 12 patients [5.5\%], $P=.004)$. Mitral valve repair was performed exclusively in the BP group (MP: 4 patients [4.3\%], BP: 31 patients $[14.2 \%], P<.006)$. A greater number of patients underwent tricuspid annuloplasty in the MP group $(P=.002)$, whereas aortic operation was performed in more patients in the BP group $(P=.048)$. The number of patients who underwent coronary artery bypass grafting was similar in both groups $(P=.698)$. 
TABLE 2. Operative data

\begin{tabular}{|c|c|c|c|c|}
\hline Variables & $\begin{array}{c}\text { Whole } \\
(\mathbf{n}=\mathbf{3 1 2})\end{array}$ & $\begin{array}{c}\text { Mechanical } \\
(n=94)\end{array}$ & $\frac{\text { Bioprosthetic }}{(\mathbf{n}=218)}$ & $P$ value \\
\hline \multicolumn{5}{|l|}{ Procedures } \\
\hline AVR & $228(73.1)$ & $45(47.9)$ & $183(83.9)$ & $<.001^{*}$ \\
\hline $\mathrm{AVR}+$ mitral valve repair & $35(11.2)$ & $4(4.3)$ & $31(14.2)$ & $.006^{*}$ \\
\hline MVR & $57(18.3)$ & $34(36.2)$ & $23(10.6)$ & $<.001^{*}$ \\
\hline DVR & $27(8.7)$ & $15(16.0)$ & $12(5.5)$ & $.004^{*}$ \\
\hline Tricuspid annuloplasty & $46(14.7)$ & $23(24.5)$ & $23(10.6)$ & $.002 *$ \\
\hline CABG & $128(41.0)$ & $37(39.4)$ & $91(41.7)$ & .694 \\
\hline Aortic operation & $18(5.8)$ & $2(2.1)$ & $16(7.3)$ & $.048^{*}$ \\
\hline \multicolumn{5}{|l|}{ Valve size } \\
\hline Aortic valve prosthesis & $20.9 \pm 1.8$ & $20.3 \pm 2.2$ & $21.1 \pm 1.6$ & $.002 *$ \\
\hline Mitral valve prosthesis & $25.9 \pm 2.2$ & $25.5 \pm 2.3$ & $26.3 \pm 2.1$ & .108 \\
\hline Operating time, $\min$ & $392.7 \pm 143.6$ & $412.1 \pm 202.6$ & $387.6 \pm 124.4$ & .407 \\
\hline CPB time, min & $180.3 \pm 66.3$ & $189.1 \pm 64.9$ & $176.5 \pm 66.6$ & .130 \\
\hline Aortic clamp time, min & $113.8 \pm 52.7$ & $139.3 \pm 71.0$ & $107.3 \pm 45.0$ & $.004^{*}$ \\
\hline \multicolumn{5}{|l|}{ Early outcomes } \\
\hline Hospital mortality & $52(16.7)$ & $14(14.9)$ & $38(17.4)$ & .578 \\
\hline Re-exploration & $13(4.1)$ & $5(5.3)$ & $8(3.7)$ & .429 \\
\hline Stroke & $19(6.1)$ & $6(6.4)$ & $13(6.0)$ & .887 \\
\hline Delirium & $20(6.4)$ & $2(2.1)$ & $18(8.3)$ & $.026^{*}$ \\
\hline Prolonged ventilation $(>48 \mathrm{~h})$ & $65(20.8)$ & $15(16.0)$ & $50(22.9)$ & .156 \\
\hline Tracheostomy & $22(7.1)$ & $3(3.2)$ & $19(8.7)$ & .061 \\
\hline Deep wound infection & $8(2.6)$ & $0(0)$ & $8(3.7)$ & $.016^{*}$ \\
\hline ICU stay, $\mathrm{d}$ & $4.0(3.0-9.8)$ & $4.0(2.0-8.0)$ & $5.0(3.0-10.5)$ & .114 \\
\hline Hospital stay, d & $24(17-41)$ & $23(18-41)$ & $24(16-41)$ & .220 \\
\hline Discharge to home & $170(66.0)$ & $52(65.0)$ & $119(66.5)$ & .816 \\
\hline
\end{tabular}

$A V R$, Aortic valve replacement; $M V R$, mitral valve replacement; $D V R$, dual valve replacement (combined AVR and MVR); $C A B G$, coronary artery bypass grafting; $C B P$, cardiopulmonary bypass; $I C U$, intensive care unit. $* P<.05$.

The mean labeled size of the prosthetic valves was $20.9 \pm 1.8 \mathrm{~mm}$ in the aortic position and $25.9 \pm 2.2 \mathrm{~mm}$ in the mitral position. In the MP group, a significantly smaller size of aortic valve prostheses was implanted (MP: $20.3 \pm 2.2 \mathrm{~mm}$, BP: $21.1 \pm 1.6 \mathrm{~mm}, P=.002$ ). In the mitral position, prosthesis size was similar in both groups.

Mean operative time was $392.7 \pm 143.6$ minutes and mean cardiopulmonary bypass time was $180.3 \pm 66.3$ minutes. Mean aortic clamp time was significantly longer in the MP group (MP: $139.3 \pm 71.0$ minutes, BP: $107.3 \pm 45.0$ minutes, $P=.004)$.

\section{Early Outcomes}

Hospital mortality resulted in 52 patients $(16.7 \%)$ and was similar across both groups (MP: $14.9 \%$ [14/94], BP: $17.4 \%$ [38/18], $P=.578$ ). The causes of hospital mortality are summarized in Table E2. Regarding postoperative complications, the incidence of delirium (MP: $2.1 \%$, BP: $8.3 \%$, $P=.026$ ) and deep wound infection (MP: $0 \%$, BP: $3.7 \%$, $P=.016)$ were significantly greater in the BP group. The BP group also required more tracheostomies in comparison with the MP group; however, this difference was not significant (MP: $3.2 \%$, BP: $8.7 \%, P=.061$ ). No significant differences were found in the incidence of other complications, such as re-exploration, stroke, prolonged ventilation ( $>48$ hours), length of intensive care unit stay, hospital stay, and the ratio of discharge to home dispositions in both groups.

\section{Late Outcomes}

Survival. During the observation period, 85 late deaths occurred, including 11 cardiac-related deaths, 6 bleedingrelated deaths, and 8 sudden deaths. The causes of late death are summarized in Table E3. Overall survival was $53.9 \pm 3.3 \%$ at 5 years and $41.5 \pm 3.7 \%$ at 10 years. Overall survival was similar in both prosthesis groups (MP: $57.4 \pm 5.5 \%$ at 5 years and $46.3 \pm 6.4 \%$ at 10 years, BP: $50.2 \pm 4.1 \%$ at 5 years and $38.8 \pm 4.5 \%$ at 10 years, $P=.305)$. Both groups had acceptable 5-year and 10 -year overall survival when compared with that of the Japanese dialysis population, adjusted for duration of hemodialysis therapy $(69.5 \%$ at 5 years and $49.3 \%$ at 10 years, mean age $67.7 \pm 1.2$ years) (Figure 1, $A$ ). When stratified by prosthetic valve position, 5 -year survival was significantly lower in patients who underwent MVR and 




A



B

FIGURE 1. Overall actual survival. A, Overall actual survival comparing patients with MP and BP (MP: $57.4 \pm 5.5 \%$ at 5 years and $46.3 \pm 6.4 \%$ at 10 years, BP: $50.2 \pm 4.1 \%$ at 5 years and $38.8 \pm 4.5 \%$ at 10 years, $P=.305$ ). The dotted line shows the survival curve for Japanese patients on dialysis matched the duration after introduction of hemodialysis treatment. B, Overall actual survival stratified with prosthetic valve location (AVR: $62.3 \pm 3.7 \%$, MVR: $31.2 \pm 7.1 \%$, DVR: $38.8 \pm 11.0 \%, P<.001)$. The dotted line shows the survival curve for Japanese patients on dialysis matched the duration after introduction of hemodialysis treatment. $M P$, Mechanical prosthesis; $B P$, bioprosthesis; $A V R$, aortic valve replacement; $M V R$, mitral valve replacement; $D V R$, combined valve replacement of AVR and MVR.

DVR (AVR: $62.3 \pm 3.7 \%$, MVR: $31.2 \pm 7.1 \%$, DVR: $38.8 \pm 11.0 \%, P<.001$ ) (Figure $1, B$ ).

Univariate Cox-hazard regression analysis revealed diabetic nephropathy (HR, 2.10; 95\% CI, 1.50-2.96,
$P<.001$ ), active infective endocarditis (HR, 2.30; 95\% CI, 1.35-3.68, $P=.003$ ), New York Heart Association (NYHA) functional classification $\geq$ III (HR, 2.91; 95\% CI, 2.02-4.15, $P<.001$ ), nonelective surgery (HR, 2.56; 
TABLE 3. Cox hazard analysis of overall survival

\begin{tabular}{|c|c|c|c|c|}
\hline \multirow[b]{2}{*}{ Variables } & \multicolumn{2}{|c|}{ Univariate } & \multicolumn{2}{|c|}{ Multivariate } \\
\hline & HR $(95 \%$ CI $)$ & $P$ value & HR $(95 \%$ CI) & $\overline{P \text { value }}$ \\
\hline Mechanical prosthesis & $0.82(0.56-1.18)$ & .301 & $0.75(0.47-1.17)$ & .206 \\
\hline Age, $y$ & $1.02(1.00-1.04)$ & .090 & $1.34(0.99-1.04)$ & .144 \\
\hline Female sex & $0.95(0.67-1.34)$ & .794 & $0.81(0.56-1.16)$ & .246 \\
\hline BSA, $\mathrm{m}^{2}$ & $0.93(0.22-4.02)$ & .927 & & \\
\hline Duration of hemodialysis, $y$ & $0.99(0.95-1.02)$ & .493 & & \\
\hline Diabetic nephropathy & $2.10(1.50-2.96)$ & $<.001 *$ & $1.90(1.31-2.73)$ & $<.001^{*}$ \\
\hline Insulin use & $1.04(0.62-1.66)$ & .864 & & \\
\hline Hypertension & $0.73(0.52-1.04)$ & .080 & & \\
\hline Dyslipidemia & $0.79(0.49-1.24)$ & .321 & & \\
\hline Previous stroke & $1.09(0.71-1.62)$ & .679 & & \\
\hline Carotid artery stenosis & $1.15(0.56-2.07)$ & .685 & & \\
\hline COPD & $1.51(0.88-2.43)$ & .128 & & \\
\hline Atrial fibrillation & $1.16(0.67-1.87)$ & .574 & & \\
\hline Coronary artery disease & $1.00(0.71-1.40)$ & .998 & & \\
\hline Peripheral artery disease & $0.94(0.57-1.46)$ & .788 & & \\
\hline Active IE & $2.30(1.35-3.68)$ & $.003^{*}$ & $1.68(0.91-2.96)$ & .093 \\
\hline NYHA $\geq$ III & $2.91(2.02-4.15)$ & $<.001 *$ & $2.16(1.37-3.35)$ & $.001^{*}$ \\
\hline Nonelective surgery & $2.56(1.79-3.61)$ & $<.001^{*}$ & $1.14(0.69-1.86)$ & .610 \\
\hline Ejection fraction, $\%$ & $0.99(0.97-1.00)$ & .098 & & \\
\hline Mitral valve replacement & $2.00(1.40-2.82)$ & $<.001 *$ & $2.36(1.58-3.49)$ & $<.001^{*}$ \\
\hline CABG & $0.89(0.63-1.26)$ & .523 & & \\
\hline Aortic operation & $0.80(0.34-1.58)$ & .545 & & \\
\hline $\mathrm{CPB}$ time & $1.00(1.00-1.00)$ & .244 & & \\
\hline Aortic clamp time & $1.00(0.99-1.00)$ & .716 & & \\
\hline
\end{tabular}

95\% CI, 1.79-4.15, $P<.001$ ), and MVR (HR, 2.00; 95\% CI, 1.40-2.82, $P<.001)$ as significant risk factors of late death (Table 3).

Multivariate Cox-hazard analysis also revealed diabetic nephropathy (HR, 1.90; 95\% CI, 1.31-2.73, $P<.001$ ), NYHA $\geq$ III (HR, 2.16; 95\% CI, 1.37-3.35, $P=.001)$, and MVR (HR, 2.36; 95\% CI, 1.58-3.49, $P<.001$ ) as significant risk factors for late death (Table 3 ).

Reoperation, bleeding, and embolic events. Seven patients required reoperation, including SVD $(B P, n=3)$, prosthetic valve endocarditis (BP, $n=1)$, pannus proliferation (MP, $n=2)$, and prosthetic valve thrombosis (MP, $\mathrm{n}=1)$. Freedom from valve-related reoperation was $98.2 \pm 1.3 \%$ at 5 -year and $85.6 \pm 5.9 \%$ at 10 -year time points. Freedom from reoperation was similar across both groups (MP: $97.4 \pm 2.5 \%$ at 5 years, BP: $98.8 \pm 1.2 \%$ at 5 years, $P=.919$ ) (Figure $2, A$ ). In our younger patient study population (age $<65$ years, MP: 63 patients and BP: 27 patients), there was no significant difference across the groups (MP: $95.7 \pm 4.3 \%$ at 5 years, BP: $100 \%$ at 5 years, $P=.351)$.

Bleeding events occurred in 19 patients (MP: 6 patients, BP: 13 patients). In the MP group, the cause of bleeding included gastrointestinal (GI) tract bleeding $(n=4)$ or hemoptysis $(\mathrm{n}=2)$. In the BP group, the source of bleeding was GI tract bleeding $(\mathrm{n}=4)$, subdural hemorrhage $(n=4)$, cerebral hemorrhage $(n=3)$, and intramuscular bleeding $(\mathrm{n}=2)$. Freedom from bleeding events was $92.3 \pm 2.3 \%$ at 5 -year and $81.1 \pm 4.6 \%$ at 10 -year time points. No significant differences were found in the incidence of bleeding events across the groups (MP: $92.8 \pm 3.7 \%$ at 5 years, BP: $92.2 \pm 2.8 \%$ at 5 years, $P=.676$ ) (Figure 2, $B$ ).

Embolic events occurred in 15 patients (MP: 10 patients, BP: 5 patients). In the MP group, the cause of embolism included cerebral infarction $(\mathrm{n}=6)$ and GI tract infarction $(n=4)$. In the BP group, the cause of embolism included cerebral infarction $(n=4)$ and acute peripheral arterial 


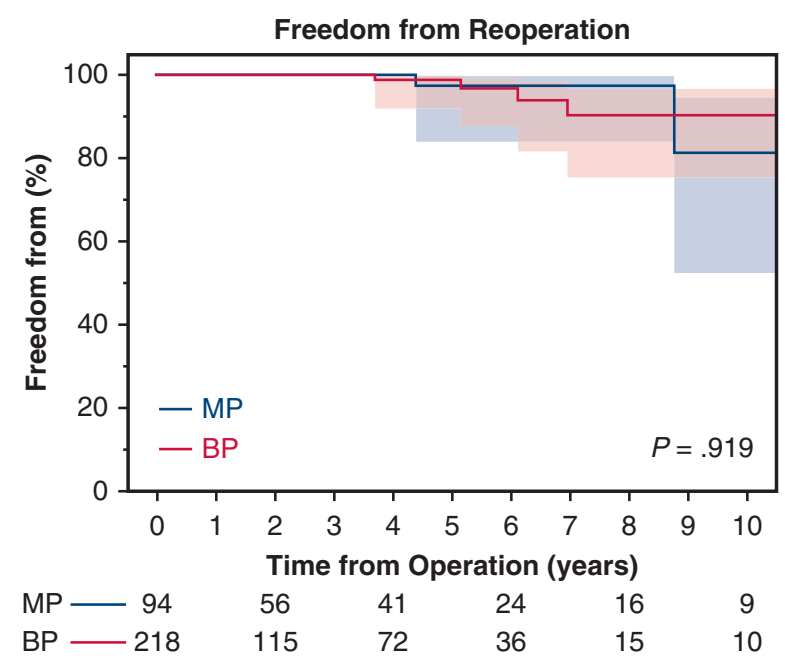

A



B

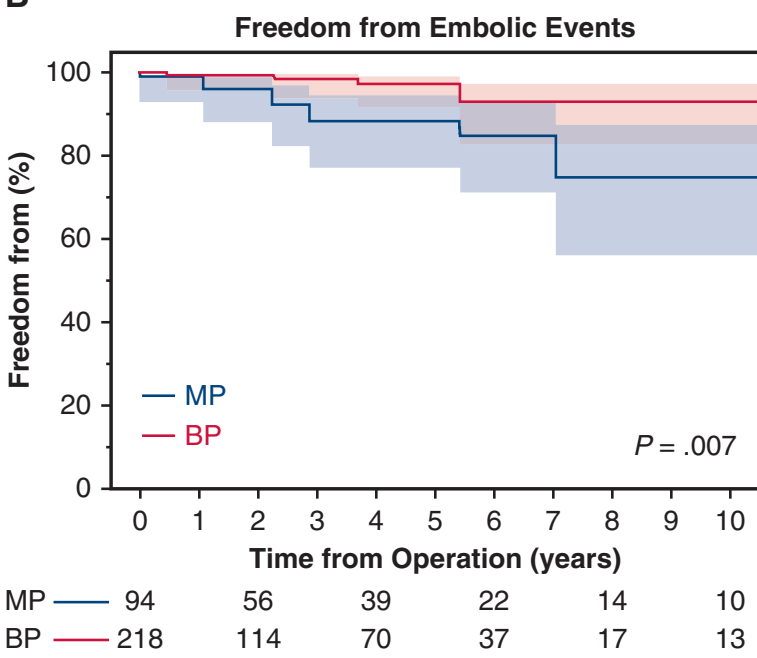

C

FIGURE 2. Freedom from valve-related events. A, Freedom from valverelated reoperation comparing patients with MP and BP (MP: $97.4 \pm 2.5 \%$ at 5 years, BP: $98.8 \pm 1.2 \%$ at 5 years, $P=.919)$. B, Freedom from occlusion $(\mathrm{n}=1)$. Freedom from embolic events was $94.2 \pm 1.8 \%$ at 5 -year and $86.2 \pm 3.9 \%$ at 10 -year time points, respectively. In the MP group, freedom from embolic events was significantly worse (MP: $88.3 \pm 4.3 \%$ at 5 years, BP: $97.2 \pm 1.6 \%$ at 5 years, $P=.007$ ) (Figure 2, C). In the subgroup analyses, freedom from embolic events was significantly greater in patients receiving BPs with AVR and noninfective endocarditis. The subgroup analysis also revealed significantly greater freedom from embolic events in both male and female patients receiving $\mathrm{BP}$ over MP (Figure E1, $A-D$ ).

\section{DISCUSSION}

Valve selection between MP and BP remains controversial. The selection of prosthetic valves is frequently determined by the risk of anticoagulation and reoperation. The Japanese Association of Thoracic Surgery 2014 annual report noted that implanted prosthetic valves consist of $4200 \mathrm{MPs}$ and 13,000 BPs, although the ratio of BP to MP implantation has increased dramatically in the last 10 years. ${ }^{15}$ Recent reports have suggested that BP is associated with a greater risk of reoperation than MP, although it has a decreased probability of bleeding or embolic events; However, a unanimous conclusion regarding valve selection has yet to be found. ${ }^{16-19}$ In a randomized trial, Goldstone and colleagues ${ }^{20}$ reported that the long-term mortality benefit associated with MP, compared with BP, persisted until 55 years of age among patients undergoing AVR and until 70 years of age for those undergoing MVR.

In contrast, other recent studies have reported that BP should be preferred over MP in patients on dialysis, given the limited life expectancy in these patients and the risk of SVD of BP. ${ }^{21-23}$ In a meta-analysis, Phan and colleagues ${ }^{11}$ demonstrated that MP and BP had similar midto long-term survival in patients on dialysis, with the BP group showing lower rates of bleeding (MP: 6.4\%, BP: $5.2 \%, P=.040$ ) and thromboembolism events (MP: $12.8 \%$, BP: $2.7 \%, P=.020$ ). On the basis of these results, European Society of Cardiology guidelines stated a favorable use of BP over MP. ${ }^{13}$ However, there is still a concern for rapid calcification of BP in patients on dialysis. ${ }^{24}$

Our results support these previous reports, showing that the BP group had a lower incidence of embolic events with no significant differences between survival and reoperation including SVD. In the subgroup analysis of younger patients $(<65$ years), the MP groups showed no survival benefit (MP, $\mathrm{n}=63: 56.3 \pm 7.2 \%$ at 5 years, $\mathrm{BP}, \mathrm{n}=27$ : $46.4 \pm 11.2 \%$ at 5 years). Moreover, the demonstrated

bleeding events (MP: $92.8 \pm 3.7 \%$ at 5 years, BP: $92.2 \pm 2.8 \%$ at 5 years, $P=$.676). C, Freedom from embolic events (MP: $88.3 \pm 4.3 \%$ at 5 years, BP: $97.2 \pm 1.6 \%$ at 5 years, $P=.007) . M P$, Mechanical prosthesis; $B P$, bioprosthesis. 
risk factors of late survival (diabetic nephropathy, preoperative congestive heart failure [NYHA $\geq \mathrm{III}]$, and concurrent MVR) may suggest that BP is more favorable in patients with a lower expected worse survival.

There is also controversy regarding the approach to anticoagulation therapy in patients on dialysis. We demonstrated that the MP group had a significantly greater risk of embolic events compared with the BP group, although the incidence of bleeding events across both groups was similar. In some guidelines for patients on dialysis with atrial fibrillation, anticoagulation therapy is not indicated, as it significantly increases not only the incidence of major hemorrhage in patients on dialysis ${ }^{25,26}$ but also the incidence of ischemic stroke. ${ }^{27,28}$ Although there are a few differences in the pathway inducing thrombin generation in patients with prosthetic valve replacement versus patients with atrial fibrillation, ${ }^{29}$ the specific features of patients on dialysis, various platelet and coagulation abnormalities, routine use of heparin, and accelerating vascular calcification due to inhibiting matrix $\operatorname{protein}^{30}$ may explain the greater incidence of thromboembolic events in patients on dialysis with MP than in the general population. In addition, subtherapeutic international normalized ratio values in patients on dialysis due to lack of compliance with anticoagulation therapy may contribute the high incidence of embolic events. Considering patients on dialysis with suboptimal anticoagulation management have a greater risk for stroke or thromboembolic events, ${ }^{27}$ the use of BP may reduce the burden of anticoagulation and the substantial risk of bleeding or thromboembolism in this patient population (Graphical Abstract).

Transcatheter valve implantation has been an attractive alternative to surgical valve replacement (SVR). Alqahtani and colleagues ${ }^{31}$ reported that transcatheter aortic valve replacement (TAVR) had significantly lower hospital mortality than SVR in patients on dialysis (TAVR: 6.1\%, SVR: $13.7 \%, P=.021)$. However, the Nationwide Inpatient Sample database in the United States reported that patients on dialysis had a greater risk of mortality after TAVR compared with patients not on dialysis. ${ }^{32}$ In our report, hospital mortality was high $(16.7 \%)$, although it was lower than the estimated mortality (Japan score 30-day mortality: $19.6 \pm 20.5 \%$ ). In regard to mid-term durability, Chakravarty and colleagues ${ }^{33}$ suggested that patients who underwent TAVR had a greater risk of subclinical leaflet thrombosis than those who underwent SVR. The use of transcatheter mitral valve replacement for dialysis patients remains controversial. Long-term evidence is required before applying these procedures to patients on dialysis.

\section{Limitations}

There were some limitations in the present study. First, it was a retrospective study. Second, 7 hospitals were included in this study, allowing for variability in the details of procedures, the selection of the prostheses, echocardiographic follow-up, and management of anticoagulation therapy. Valve selection may include a bias, although it was primarily determined according to patient age. We did not have the data regarding patient compliance with anticoagulation therapy and the severity of patient condition because surgeon preference may be influenced with taking into these factors. We did not have adequate echocardiographic follow-up data that could diagnose SVD more precisely in the BP group.

Third, we included AVR, MVR, and DVR in the same cohort, given the infrequency of valve replacement surgery in patients on dialysis. Other studies thus far have not evaluated valve-related complications and have used smaller patient population than our current study. ${ }^{22}$ Lastly, there were some differences in patient characteristics across groups. Although we performed multivariate Cox hazard analysis, several selection biases remained. We did not have the data regarding the differences between disease processes. Age was a variable that this study could not overcome because of the study design. Although our data suggest that BP group had an advantage in preventing embolic events, this is speculative. The expected bias favors MP over BP, given that patients with an expectation of longer survival or small annular diameter likely receive a MP over a BP.

\section{CONCLUSIONS}

In our 16-year study, the outcomes of heart valve replacement in patients on dialysis are acceptable. Valve selection is not associated with late survival in patients on dialysis, although diabetic nephropathy, preoperative congestive heart failure, and concurrent MVR may be significant risk factors for late death. In patients on dialysis with high risk factors, BP may have an advantage in preventing embolic events without increasing the incidence of valverelated reoperation.

\section{Conflict of Interest Statement}

Authors have nothing to disclose with regard to commercial support.

\section{References}

1. Masatane I, Nakai S, Ogata, Kimata N, Hanafusa N, Hamano T, et al. An overview of regular dialysis treatment in Japan (as of 31 December 2013). Ther Apher Dial. 2015;19:540-74.

2. Wakasugi M, Kazama JJ, Narita I. Anticipated increase in the number of patients who require dialysis treatment among the aging population of Japan. Ther Apher Dial. 2015;19:201-6.

3. Straumann E, Meyer B, Misteli M, Blumberg A, Jenzer HR. Aortic and mitral valve disease in patients with end stage renal failure on long-term haemodialysis. Br Heart J. 1992;67:236-9.

4. Blacher J, Guerin AP, Pannier B, Marchais SJ, London GM. Arterial calcifications, arterial stiffness, and cardiovascular risk in end-stage renal disease. Hyper tension. 2001;38:938-42. 
5. Ohara T, Hashimoto Y, Matsumura A, Suzuki M, Isobe M. Accelerated progression and morbidity in patients with aortic stenosis on chronic dialysis. Circ J. 2005;69:1535-9.

6. Kawase Y, Taniguchi T, Morimoto T, Kadota K, Iwasaki K, Kuwayama A, et al. Severe aortic stenosis in dialysis patients. J Am Heart Assoc. 2017;6.

7. Thourani VH, Sarin EL, Kilgo PD, Lattouf OM, Puskas JD, Chen EP, et al. Shortand long-term outcomes in patients undergoing valve surgery with end-stage renal failure receiving chronic hemodialysis. J Thorac Cardiovasc Surg. 2012; 144:117-23.

8. Okada N, Tajima K, Takami Y, Kato W, Fujii K, Hibino M, et al. Valve selection for the aortic position in dialysis patients. Ann Thorac Surg. 2015;99:1524-31.

9. Takemura H. Selection of artificial valve for the patients on hemodialysis. Gen Thorac Cardiovasc Surg. 2013;61:314-9.

10. Nishimura R, Otto C, Bonow R, Carabello B, Erwin J, Guyton R. American College of Cardiology/American Heart Association task force on practice guidelines 2014 AHA/ACC guideline for the management of patients with valvular heart disease: executive summary: a report of the American College of Cardiology/ American Heart Association task force on practice guidelines. J Am Coll Cardiol. 2014;63:2438-88.

11. Phan K, Zhao DF, Zhou JJ, Karagaratnam A, Phan S, Yan TD. Bioprosthetic versus mechanical prostheses for valve replacement in end-stage renal disease patients: systematic review and meta-analysis. J Thorac Dis. 2016;8:769-77.

12. Okita Y, Okada Y, Otsuji Y, Komeda M, Nakatani S, Matsuzaki M, et al. Guidelines for surgical and interventional treatement of valvular heart disease (JCS2012). Jpn Circ Soc. 2012;42:1-75.

13. Vahanian A, Alfieri O, Andreotti F, Antunes MJ, Barón-Esquivias G, Baumgartner $\mathrm{H}$, et al. Guidelines on the management of valvular heart disease (version 2012). Euro Heart J. 2012:33:2451-96.

14. The Japanese Society of Dialysis Therapy Life Tables. Available at: http://docs jsdt.or.jp/overview/. Accessed December 31, 2011.

15. Masuda M, Okumura M, Doki Y, Endo S, Hirata Y, Kobayashi J, et al. Thoracic and cardiovascular surgery in Japan during 2014: annual report by the Japanese Association for Thoracic Surgery. Gen Thorac Cardiovasc Surg. 2016;64: 665-97.

16. Badhwar V, Ofenloch JC, Rovin JD, van Gelder HM, Jacobs JP. Noninferiority of closely monitored mechanical valves to bioprostheses overshadowed by early mortality benefit in younger patients. Ann Thorac Surg. 2012;93: 748-53.

17. Brennan JM, Edwards FH, Zhao Y, O’Brien S, Booth ME, Dokholyan RS, et al. Ten-year comparison of pericardial tissue valves versus mechanical prostheses for aortic valve replacement in patients younger than 60 years of age. J Thorac Cardiovasc Surg. 2012;144:1075-83.

18. Brennan JM, Edwards FH, Zhao Y, et al. Long-term safety and effectiveness of mechanical versus biologic aortic valve prostheses in older patients: results from the Society of Thoracic Surgeons adult cardiac surgery national database. Circulation. 2013;127:1647-55.

19. Ikeno Y, Okita Y. Long-term results of aortic valve replacement. Mechanical prostheses vs. bioprostheses. Circ J. 2014;78:2627-30.
20. Goldstone AB, Chiu P, Baiocchi M, Lingala B, Patrick WL, Fischbein MP, et al Mechanical or biologic prostheses for aortic-valve and mitral-valve replacement. N Engl J Med. 2017;377:1847-57.

21. Kaplon RJ, Cosgrove DM III, Gillinov AM, Lytle BW, Blackstone EH, Smedira NG. Cardiac valve replacement in patients on dialysis: influence of prosthesis on survival. Ann Thorac Surg. 2000;70:438-41.

22. Chan V, Jamieson WR, Fleisher AG, Denmark D, Chan F, Germann E. Valve replacement surgery in end-stage renal failure: mechanical prostheses versus bioprostheses. Ann Thorac Surg. 2006;81:857-62.

23. Williams ML, Bavaria JE, Acker MA, Desai ND, Vallabhajosyula P, Hargrove WC, et al. Valve selection in end-stage renal disease: should it always be biological? Ann Thorac Surg. 2016;102:1531-5.

24. Lamberti JJ, Wainer BH, Fisher KA, Karunaratne HB, Al-Sadir J. Calcific stenosis of the porcine heterograft. Ann Thorac Surg. 1979;28:28-32.

25. Herzog CA, Singer RW, Berger AK, Charytan BM, Diez J, Hart RG, et al. Cardiovascular disease in chronic kidney disease. A clinical update from kidney dis ease: improving global outcomes (KDIGO). Kidney Int. 2011;80:572-86.

26. Hirakata H, Nitta K, Tomo T, Akiba T, Ikari Y, Iseki K, et al. Clinical guidelines for the evaluation and the treatment of cardiovascular complications in hemodialysis patients. J Jpn Soc Dial Ther. 2011;44:337-425.

27. Chan KE, Lazarus JM, Thadhani R, Hakim RM. Warfarin use associates with increased risk for stroke in hemodialysis patients with atrial fibrillation. $J$ Am Soc Nephrol. 2009;20:2223-33.

28. Lee M, Saver JL, Hong KS, Wu YJ, Huang WH, Rao NM, et al. Warfarin use and risk of stroke in patients with atrial fibrillation undergoing hemodialysis: a metaanalysis. Medicine. 2016;95:e2741.

29. Jaffer IH, Stafford AR, Fredenburgh JC, Whitlock RP, Chan NC, Weitz JI. Dabigatran is less effective than warfarin at attenuating mechanical heart valveinduced thrombin generation. J Am Heart Assoc. 2015;4:e002322.

30. Reynolds JL, Joannides AJ, Skipper JN, McNair R, Schurgers LJ, Proudfoot D, et al. Human vascular smooth muscle cells undergo vesiclemediated calcification in response to changes in extracellular calcium and phosphate concentrations: a potential mechanism for accelerated vascular calcification in ESRD. J Am Soc Nephrol. 2004:15:2857-67.

31. Alqahtani F, Aljohani S, Boobes K, Maor E, Sherieh A, Rihal CS, et al. Outcomes of transcatheter and surgical aortic valve replacement in patients on maintenance dialysis. Am J Med. 2017;130:1464.e1-1411.

32. Bhatia N, Agrawal S, Yang S, Yadav K, Agarwal M, Garg L, et al. In-hospital outcomes of transcatheter aortic valve implantation in patients with end-stage renal disease on dialysis from a large national database. Am J Cardiol. 2017; 120:1355-8.

33. Chakravarty T, Søndergaard L, Friedman J, De Backer O, Berman D, Kofoed KF, et al. Subclinical leaflet thrombosis in surgical and transcatheter bioprosthetic aortic valves: an observational study. Lancet. 2017;389:2383-92.

Key Words: aortic valve replacement, mitral valve replacement, hemodialysis, end-stage renal failure 


\section{Subgroup Analysis for Valve Position}


A

FIGURE E1. Subgroup analysis for embolic events comparing MP and BP. A, Subgroup analysis for valve position. Freedom from embolic events in patients with AVR (MP: $88.8 \pm 5.4 \%$ at 5 years, BP: $96.8 \pm 1.9 \%$ at 5 years, $P=.004$ ), MVR (MP: $90.1 \pm 7.2 \%$ at 5 years, BP: $100 \%$ at 4 years, $P=.279$ ), and DVR (MP: $100 \%$ at 5 years, BP: $100 \%$ at 5 years, $P=.182$ ). B, Subgroup analysis for IE. Freedom from embolic events in patients with non-IE (MP: $91.6 \pm 3.7 \%$ at 5 years, BP: $99.3 \pm 0.7 \%$ at 5 years, $P=.040$ ) and IE (MP: $100 \%$ at 2 years, BP: $100 \%$ at 2 years, $P=.114$ ). C, Subgroup analysis for age. Freedom from embolic events in patients aged $<65$ years (MP: $91.4 \pm 4.2 \%$ at 5 years, BP: $100 \%$ at 5 years, $P=.116$ ) and $\geq 65$ years (MP: $88.9 \pm 7.4 \%$ at 5 years, BP: $99.3 \pm 7.4 \%$ at 5 years, $P=.163)$. D, Subgroup analysis for sex. Freedom from embolic events in male (MP: $89.8 \pm 4.9 \%$ at 5 years, BP: $98.5 \pm 1.5 \%$ at 5 years, $P=.037$ ) and female patients (MP: $91.5 \pm 6.0 \%$ at 5 years, BP: $95.4 \pm 3.3 \%$ at 5 years, $P=.036$ ). AVR, Aortic valve replacement; $M P$, mechanical prosthesis; $B P$, bioprosthesis; $M V R$, mitral valve replacement; $D V R$, combined valve replacement of AVR and MVR; IE, infective endocarditis. 


\section{Subgroup Analysis for Infective Endocarditis}
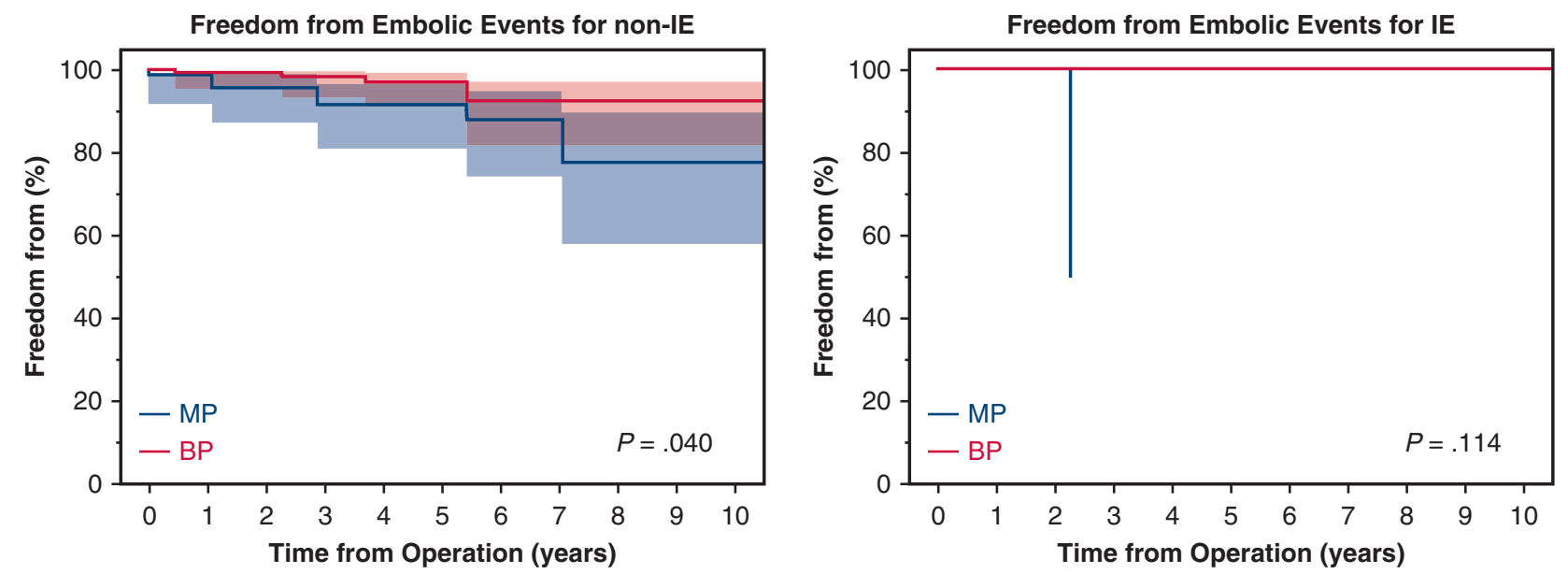

$\begin{array}{lccccc}\text { MP }-80 & 54 & 39 & 22 & 14 & 10 \\ \text { BP } 209 & 109 & 65 & 36 & 16 & 12\end{array}$

B

Subgroup Analysis for Age
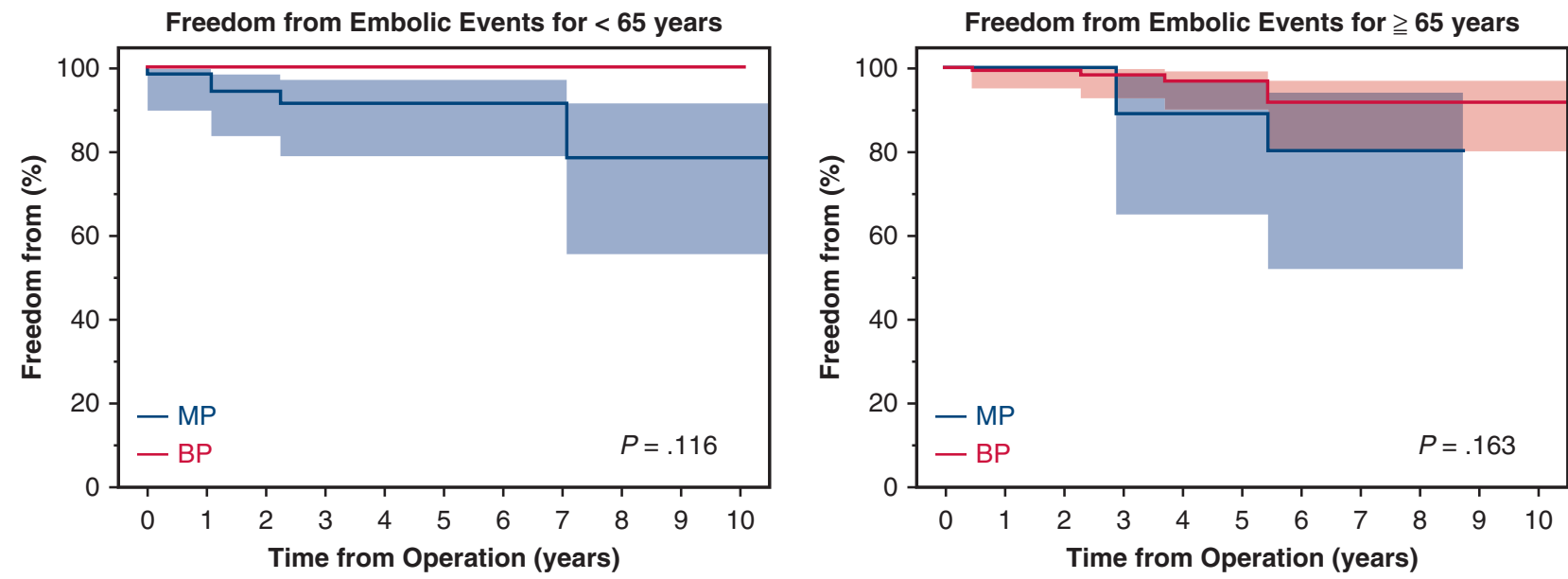

$\begin{array}{cccccc}\mathrm{MP}-63 & 38 & 25 & 15 & 11 & 10 \\ \mathrm{BP}-27 & 20 & 12 & 6 & 3 & 3\end{array}$

C

FIGURE E1. (Continued). 


\section{Subgroup Analysis for Gender}
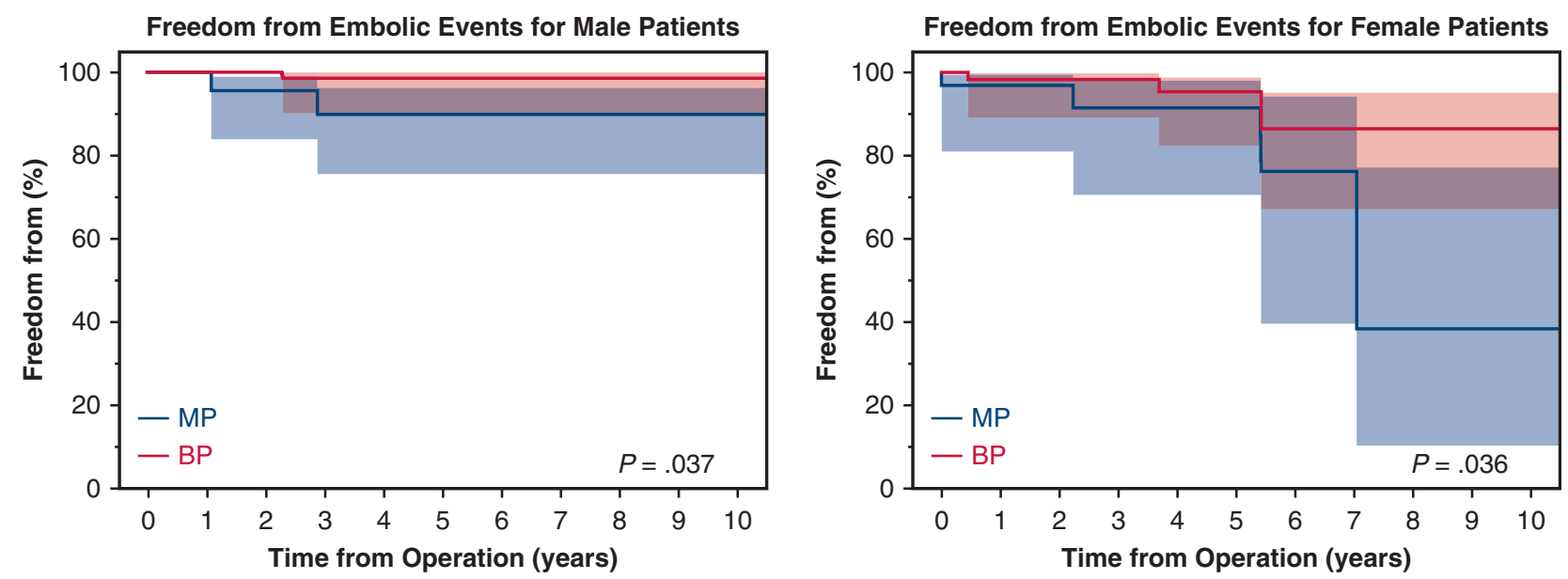

$\begin{array}{llllll}\text { MP }-62 & 38 & 28 & 18 & 12 & 8 \\ \mathrm{BP}-124 & 73 & 44 & 21 & 12 & 8\end{array}$

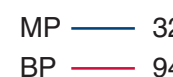

Time from Operation (years)

$\begin{array}{lllllll}\mathrm{BP} & -124 & 73 & 44 & 21 & 12 & 8\end{array}$

FIGURE E1. (Continued). 
TABLE E1. Implanted valves

\begin{tabular}{lrcc}
\hline \multicolumn{1}{c}{ Variables } & AVR & MVR & DVR \\
\hline BP & & & \\
CEP (Standard Magna, & 131 & 8 & 9 \\
$\quad$ Magna EASE) & & & \\
Trifecta & 14 & 0 & 0 \\
Mitroflow & 7 & 0 & 0 \\
Mosaic (Standard, Ultra) & 20 & 4 & 3 \\
Epic & 2 & 11 & 0 \\
Freestyle & 2 & 0 & 0 \\
MP & & & \\
SJM & 16 & 18 & 8 \\
On-X & 8 & 16 & 6 \\
ATS (Standard, AP) & 10 & 0 & 1 \\
CM (Standard, TopHat) & 4 & 0 & 3 \\
Advantage & 1 & 0 & 0 \\
MIRA & 0 & 2 & 0 \\
\hline
\end{tabular}

$A V R$, Aortic valve replacement; $M V R$, mitral valve replacement; $D V R$, dual valve replacement (combined AVR and MVR); $B P$, bioprosthesis; $M P$, mechanical prosthesis.
TABLE E3. Cause of late death

\begin{tabular}{lccc}
\hline & Whole & MP & BP \\
\cline { 2 - 4 }$(\mathbf{n}=\mathbf{8 5})$ & $(\mathbf{n}=\mathbf{2 8})$ & 3 & 8 \\
\hline Cardiac & 11 & 4 & 2 \\
\hline Bleeding & 6 & 0 & 3 \\
Cerebrovascular & 3 & 0 & 1 \\
Vascular & 1 & 1 & 3 \\
\hline Malignancy & 4 & 1 & 8 \\
Pulmonary & 9 & 2 & 0 \\
Gastrointestinal & 2 & 5 & 2 \\
Renal & 7 & 2 & 6 \\
Sepsis & 8 & 2 & 6 \\
\hline Sudden death & 8 & 8 & 18 \\
\hline Unknown & 26 & &
\end{tabular}

TABLE E2. Cause of hospital mortality

\begin{tabular}{lccc}
\hline & Whole & MP & BP \\
\cline { 2 - 4 } & $(\mathbf{n = 5 2 )}$ & $(\mathbf{n = 1 4 )}$ & $\frac{(\mathbf{n}=\mathbf{3 8})}{}$ \\
\hline LOS & 7 & 2 & 5 \\
DSWI & 2 & 0 & 2 \\
Sepsis & 6 & 1 & 5 \\
Bowel necrosis & 2 & 0 & 2 \\
Pneumonia & 3 & 0 & 3 \\
Pancreatitis & 1 & 0 & 1 \\
LV rupture & 1 & 1 & 0 \\
Unknown & 30 & 10 & 20 \\
\hline
\end{tabular}

$M P$, Mechanical prosthesis; $B P$, bioprosthesis; $L O S$, low cardiac output syndrome; $D S W I$, deep sternal wound infection; $L V$, left ventricle. 